\title{
Family histories of Type II diabetes and hypertension predict intima-media thickness in patients with Type I diabetes
}

\author{
S. Mäkimattila' ${ }^{1}$, K. Ylitalo² ${ }^{2}$ A. Schlenzka ${ }^{1}$, M.-R. Taskinen ${ }^{2}$, P. Summanen ${ }^{3}$, M. Syvänne ${ }^{2}$, H. Yki-Järvinen ${ }^{1}$ \\ Department of Medicine, Divisions of ${ }^{1}$ Diabetes, ${ }^{2}$ Cardiology, and ${ }^{3}$ Department of Ophthalmology, \\ Helsinki University Central Hospital, Helsinki, Finland
}

\section{Abstract}

Aims/hypothesis. Hyperglycaemia predicts microvascular complications but data on macrovascular disease are limited. We searched for predictors of carotid artery intima-media thickness in young adults with Type I (insulin-dependent) diabetes mellitus.

Methods. A total of 71 children $(\mathrm{F} / \mathrm{M}=34 / 37)$ were followed after their diagnosis until they reached $32 \pm$ 1 years of age, when duration of diabetes averaged $22 \pm 1$ years. Cardiovascular risk markers [lipids, blood pressure, smoking, urinary albumin excretion rate, lifetime glycaemic exposure ( $A_{1 c}$ months), exercise habits, alcohol consumption, family history] were evaluated at age $21 \pm 1$ for the baseline examination and at age $32 \pm$ 1 years for the follow-up examination years. During follow-up, intima-media thickness of common and internal carotid arteries and the carotid bulb were quantitated using a high-resolution B-mode ultrasound.

Results. In univariate analysis, age, BMI, blood pressure, lifetime glycaemic exposure, a positive family history of Type II (non-insulin-dependent) diabetes mellitus, hypertension and cardiovascular disease were predictors of carotid intima-media thickness. In multivariate analysis, a positive family history of Type II diabetes predicted maximal $(p<0.05)$ and common $(p<0.005)$ carotid artery intima-media thickness, family history of hypertension predicted increases in maximal $(p<0.04)$, and far wall $(p<0.006)$ carotid artery intima-media thickness, and lifetime glycaemic exposure was an independent predictor of increased carotid bulb thickness $(p<0.03)$.

Conclusion/interpretation. Positive family histories of Type II diabetes and hypertension are independent predictors of carotid intima-media thickness in patients with Type I diabetes, and could therefore predispose these patients to atherosclerosis [Diabetologia (2002) 45:711-718]

Keywords Atherosclerosis, cardiovascular risk, glucose, ultrasound.
The mortality and morbidity from cardiovascular disease is two to four times higher in patients with Type I

Received: 9 October 2001 / Revised: 28 January 2002

Published online: 17 April 2002

(C) Springer-Verlag 2002

Corresponding author: H. Yki-Järvinen MD, University of Helsinki, Department of Medicine, Division of Diabetes, P.O. Box 340, 00029 HUCH, Helsinki, Finland, e-mail: ykijarvi@helsinki.fi

Abbreviations: CB, Carotid bulb; CCA, common carotid atery; ETDRS, Early Treatment of Diabetic Retinopathy Study; ICA internal carotid artery; IMT, intima-media thickness; UAER, urinary albumin excretion rate (insulin-dependent) diabetes mellitus compared with healthy subjects matched for age [1]. This increase can in part be attributed to hypertension [2] and diabetic nephropathy [3]. However, in a recent Finnish population-based prospective study, poor glycaemic control predicted cardiovascular events in patients with Type I diabetes without nephropathy [4]. Furthermore, a positive family history of Type II (non-insulindependent) diabetes mellitus has been associated with an increased risk of coronary artery disease in Type I diabetic patients [5].

Measurement of intima-media thickness (IMT) has been used to quantitate subclinical atherosclerosis [6]. In non-diabetic subjects, age, male gender, hyperten- 
sion, smoking, impaired fibrinolysis, hypercholesterolaemia, and mild hyperglycaemia seem to be independent predictors of IMT $[7,8,9,10,11,12]$. In cross-sectional studies, carotid IMT has been increased in Type I diabetic patients compared with matched control subjects [13] already at a young age [14], and in the absence of overt macrovascular disease [15]. Multivariate analyses have shown that maximum or mean IMT of proximal carotid artery are independently associated with age $[13,14,16,17,18$, 19], duration of diabetes [13], male gender [13, 19], triglycerides [13], total and LDL cholesterol [18], nephropathy [13], hypertension [18, 19, 20], height [16], BMI [16], $\mathrm{HbA}_{1 \mathrm{c}}$ [17], and smoking [16] in patients with Type I diabetes.

Prospective data on predictors of carotid IMT in patients with Type I diabetes are sparse. In a recent 2-year follow-up study, carotid IMT increased by $14 \%$ in patients with Type I diabetes but did not change in healthy subjects during that time [15]. No significant correlations with changes in blood pressure, heart rate, daily dose of insulin, serum total cholesterol or measurements of glycaemia and IMT were found. In the participants of the DCCT, carotid IMT was not influenced by 6.5 years of either intensive or conventional therapy, nor was it correlated with mean $\mathrm{HbA}_{1 \mathrm{c}}$ concentrations in the entire study group [16]. In another study, however, Type I diabetic patients who had been treated with intensive insulin treatment for 10 years had a thinner common carotid IMT than those who received standard therapy [20]. The reason for the difference in these results is not clear. In both the DCCT [16] and UKPDS [21], the effect of good glycaemic control on macrovascular events was borderline whereas effects on microvascular complications were highly significant. These data might suggest that chronic hyperglycaemia is a weak risk factor for macrovascular disease, i.e. it takes a considerable amount of time before effects of chronic hyperglycaemia on macrovascular disease become evident. The aim of our study was to determine predictors of carotid IMT in patients with Type I diabetes, who were followed from the time of their diagnosis up to a mean disease duration of 22 years.

\section{Subjects and methods}

Subjects and study design. A total of 226 patients were diagnosed with Type I diabetes between the years 1968 to 1978 at the Children's Hospital of the Helsinki University Central Hospital and at the Aurora Hospital. This population represented all newly-diagnosed Type I diabetic patients younger than 15 years of age living in the Helsinki area at that time. At the first examination 22 patients of the original cohort could not be located and five had died. A total of 125 patients volunteered to participate in a baseline examination, whereby possible predictors of IMT [lipids, blood pressure, urinary albumin excretion rate (UAER), glycosylated haemoglobin] were examined at the age of $21 \pm 1$ years, when duration of diabetes averaged
$12 \pm 1$ years. The patients who did not volunteer to participate were similar with respect to gender, age and duration of diabetes to those volunteering to participate.

At the time of a follow-up examination 10 years later, five male patients had died: two because of a cardiovascular cause at ages of 22 and 31 years, and three at ages of 29, 31, and 32 years of an unknown cause. Three patients were excluded because of other illnesses or pregnancy, five patients had moved, and 19 patients could not be located. A total of 71 (76\% of those invited) patients volunteered to participate in the follow-up examination at the mean age of $32 \pm 1$ years. Compared with the patients participating in both examinations $(n=$ $71)$, the patients studied only at baseline $(n=54)$ had similar demographic characteristics gender, M/F $37 / 34$ vs 26/28; age $21 \pm 1$ vs $21 \pm 1$ years; BMI $22.1 \pm 0.3$ vs $22.6 \pm 0.4 \mathrm{~kg} / \mathrm{m}^{2}$, and were also comparable by pubertal stage, duration of diabetes, blood pressure, $\mathrm{HbA}_{1}$, total and $\mathrm{HDL}$ cholesterol, insulin dose per kg body weight, and UAER (data not shown). At the follow-up examination common, internal and bulb IMT were measured using a high-resolution B-mode ultrasound device. Measurements of lipids, blood pressure, UAER and glycosylated haemoglobin were repeated. Electrocardiograms were analysed in a blinded fashion. Current and historical physical activity [22], smoking and alcohol consumption, and family history of Type II diabetes, hypertension and cardiovascular disease $(0=$ no family history of disease, $1=$ one parent affected, $2=$ both parents affected) were recorded. Lifetime glycaemic exposure $\left(\mathrm{A}_{1 \mathrm{c}}\right.$ months) was calculated (vide infra).

No patient had symptoms or signs of cerebrovascular or coronary heart disease (Minnesota Codes A3.1.2.1, A3.1.2.4, A3.1.2.4, A3.1.2.5, and A3.1.2.7) [23] at either examination. Two patients during the baseline examination and 20 patients during the follow-up examination were using one or several antihypertensive drugs (17 angiotensin-converting enzyme inhibitors, 7 diuretics, 5 calcium-channel blockers, and $2 \beta$ blockers), for $5 \pm 1$ years. Two patients were using lipid-lowering drugs at the time of the follow-up examination. Informed written consent was obtained after the purpose, nature and potential risks were explained to the participants. The protocol was approved by the ethics committees of Helsinki City and Helsinki University Central Hospitals.

Ultrasonographic assessment of carotid artery intima-media thickness. Ultrasound scanning was carried out with an Acuson 128XP/10 ultrasound system (Acuson Corporation, Mountain View, Calif., USA) equipped with a $7 \mathrm{MHz}$ linear array transducer. Scannings were videotaped with a Panasonic 625 PAL S-VHS-VCR, Matsushita Electric Industrial, Osaka, Japan). One physician (K. Ylitalo) carried out all ultrasound examinations. Patients were examined in the supine position with the head turned $45^{\circ}$ away from the side being scanned. Longitudinal images from three projections (anterolateral, lateral, and posterolateral) were displayed for each of the six arterial segments: right and left distal $1 \mathrm{~cm}$ of common carotid artery (CCA), the entire carotid bulb (CB), and the proximal internal carotid artery (ICA). Images were focused at both the far wall and the near wall in CCA and CB. In ICA, scanning was focused only at the far wall. IMT measurements were done by a single reader at Oy Jurilab (www.jurilab.com). IMT was measured from ultrasound images with a PC computer with a video frame grabber interfaced to a S-VHS VCR. The Prosound software (Caltech, Pasadena, Calif., USA) [24] was used to measure the IMTs at a total of 18 (or fewer) sites: far wall and near wall of CCA and $\mathrm{CB}$ from the two best projections chosen by the reader based on the visualisation of the interfaces and the maximal thickness of the IMT. In ICA, the single, best visualised projection of the far wall was measured. All measure- 
ments were done in the diastole, when IMT is at its largest. Three variables were derived from each measurement: the minimum, the mean, and the maximum IMT. All outcome variables were first calculated for each subject. The average of all mean IMT measurements (mean IMT) over 18 sites, the average of maximum IMTs (maximal IMT) over 18 sites, the average of mean far wall IMTs (far wall IMT), and the average of maximum IMTs for each segment [CCA IMT, 8 sites; CB IMT, 8 sites; ICA IMT, 2 sites). Intra-sonographer variability in the scans was estimated by scanning six patients $(8 \%)$ twice on two different occasions. The average coefficient of variation of the different outcome variables was $3.5 \pm 0.9 \%$. For the reader, the coefficient of variation for the two paired readings was 1.5 $\pm 0.5 \%$.

Assessment of diabetic microvascular complications. For nephropathy, during the baseline examination and the follow-up examination, urine was collected three times overnight consecutively to assess the UAER using radioimmunoassay and an antiserum against human albumin (albumin antiserum, Orion Diagnostica, Espoo, Finland). Microalbuminuria was defined as a mean urinary albumin excretion rate of $20-200 \mu \mathrm{g} / \mathrm{min}$, and macroalbuminuria as a rate greater than $200 \mu \mathrm{g} / \mathrm{min}$ in at least two of three consecutive overnight urine samples [25].

For retinopathy fundus photographs were taken through maximally dilated pupils during both examinations. Quantitation of the severity of retinopathy at the baseline and follow-up examination was done using the Early Treatment of Diabetic Retinopathy Study (ETDRS) [26] by the same ophthalmologist.

Glycaemic control. Glycosylated haemoglobin $\left(\mathrm{HbA}_{1}\right)$ was measured until 1987 using microcolumn chromatography with Quick-Step columns (Isolab, Akron, Ohio, USA). In 1987, the $\mathrm{HbA}_{1}$ assay was replaced by measuring $\mathrm{HbA}_{1 \mathrm{C}}$ using HPLC (BioRad, Richmond, Calif., USA). During 1987 both $\mathrm{HbA}_{1}$ and $\mathrm{HbA}_{1 \mathrm{C}}$ were measured. These data were used to convert $\mathrm{HbA}_{1}$ to $\mathrm{HbA}_{1 \mathrm{C}}$ values: $\mathrm{HbA}_{1 \mathrm{C}}=-0.219+0.886 \mathrm{HbA}_{1}(r=$ $0.96, n=110, p<0.0001)$. The intraindividual $\mathrm{CV}$ of measured and calculated $\mathrm{HbA}_{1 \mathrm{C}}$ values was $7.0 \pm 0.4 \%$. Lifetime glycaemic exposure was calculated by multiplying the number of $\mathrm{HbA}_{1 \mathrm{C}}$ units above the upper limit of normal $(6.0 \%)$ by the number of months between the preceding and succeeding intervals ( $\mathrm{A}_{1 \mathrm{C}}$ months) [27]. At least one yearly $\mathrm{HbA}_{1 \mathrm{C}}$ measurement was available in $58 \%$ of the patients during the first 6 years of the disease (the lack of data is mostly due to diagnosis before $\mathrm{HbA}_{1}$ measurements were available), $83 \%$ during years 7 to 12 of the disease, and in all patients for the rest of the duration of disease.

Other laboratory analyses. Venous blood samples were collected after a 10- to 12-h fast. During the baseline and followup examinations, serum concentrations of triglycerides, total and HDL cholesterol were determined by enzymatic colorimetric assays (Boehringer Mannheim, Mannheim, Germany and Hoffman La Roche; Diagnostica, Basel, Switzerland). Lowdensity lipoprotein cholesterol was calculated [28].

Statistical methods. Data between the two examinations and genders were compared using a Student's $t$ test. Data between tertiles were analysed using analysis of variance followed by pairwise comparison using Fischer's Exact test. UAER and serum triglyceride concentrations were log-transformed because of their non-normal distribution before analysis. Simple correlations were calculated using Spearman's rank correlation coefficient. Multivariate linear regression analysis was used for the causes of variation in parameters of IMT and selected variables. Normally distributed data are expressed as means \pm
SEM. For non-normally distributed data, the median and the interquartile range $(25 \%, 75 \%)$ are given.

\section{Results}

Patient characteristics. Patient characteristics during the baseline and the follow-up examination are shown (Table 1). Cumulative lifetime glycaemic exposure ranged between 170 to $2184 \mathrm{~A}_{1 \mathrm{C}}$ months and did not differ between women $(995 \pm 71)$ and men $(891 \pm 59)$, though women had higher $\mathrm{HbA}_{1 \mathrm{C}}$ than men $(9.7 \pm 0.3$ vs $8.9 \pm 0.2 \%, p<0.05)$ at the baseline. Men used more alcohol than women $(7.9 \pm 1.3$ vs $3.5 \pm 0.8$ drinks per week, $p<0.01)$. Lifetime smoking in pack-years was $3.3 \pm 0.7$ and did not differ between women and men. Women had a higher retinopathy (ETDRS) score $(26 \pm 3$ vs $18 \pm 2, p<0.05)$ than men at the time of the baseline examination. The ETDRS score increased during the 10-year period (Table 1, NS between men and women). During the baseline examination $74 \%$ of the patients had normoalbuminuria, $20 \%$ had microalbuminuria, and $7 \%$ had macroalbuminuria. Ten years later these prevalences were $76 \%, 11 \%$, and $13 \%$ respectively. Of the patients $18 \%$ had a positive family history (first degree relative) of Type II diabetes, $44 \%$ had hypertension, and $25 \%$ had cardiovascular disease.

Relation between clinical and biochemical characteristics and IMT. Mean, maximal and far-wall carotid artery IMT averaged $0.64 \pm 0.01,0.81 \pm 0.01$, and $0.64 \pm 0.01 \mathrm{~mm}$. IMT of the common and internal carotid arteries averaged $0.79 \pm 0.01$ and $0.73 \pm$ $0.01 \mathrm{~mm}$, and of carotid bulb $0.87 \pm 0.02 \mathrm{~mm}$. No patient had plaques in their carotid arteries. Biochemical and clinical parameters which correlated with at least one measure of carotid IMT are listed (Table 2). Such parameters included age, age of onset of diabetes, glycaemic exposure, BMI, mean arterial blood pressure, family history of Type II diabetes (Fig. 1), family history of hypertension (Fig. 1), and family history of cardiovascular disease.

A multiple linear regression analysis was done to establish independent predictors of IMT. The variables which were significant in univariate analysis (Table 2) were included in the model. In multiple linear regression analysis, age was an independent predictor of common $(r=0.30, p<0.03)$ and internal $(r=0.34$, $p<0.05)$ carotid artery IMTs. Family history of Type II diabetes was an independent predictor of mean $(r=$ $0.21, p<0.04)$, maximal $(r=0.22, p<0.04)$, and common $(r=0.32, p<0.002)$ carotid artery IMTs. Family history of hypertension predicted independently mean $(r=0.21, p<0.05)$, maximal $(r=0.21, p<$ $0.04)$, and far wall ( $r=0.29, p<0.008)$, and carotid bulb $(r=0.24, p<0.05)$ IMTs. Lifetime glycaemic exposure $\left(\mathrm{A}_{1 \mathrm{c}}\right.$ months $)$ predicted independently IMT of carotid bulb $(r=0.29, p<0.03)$, and BMI of far 
Table 1 Characteristics of Type I diabetic patients $(n=71)$ at baseline examination and 10 years later at the follow-up examination

\begin{tabular}{|c|c|c|}
\hline Characteristic & Baseline & Follow-up \\
\hline Age at onset of DM (years) & $9 \pm 1$ & \\
\hline Age (years) & $21 \pm 1$ & $32 \pm 1 * * *$ \\
\hline Height $(\mathrm{cm})$ & $169 \pm 1$ & $171 \pm 1 *$ \\
\hline Weight $(\mathrm{kg})$ & $64 \pm 1$ & $74 \pm 1 * * *$ \\
\hline $\mathrm{A}_{1 \mathrm{C}}$ months $\mathrm{b}$ [range] & $523 \pm 28[89-1168]$ & $941 \pm 46[170-2184] * * *$ \\
\hline Insulin dose (IU/day) & $51 \pm 2$ & $53 \pm 2$ \\
\hline Insulin dose (IU/kg·day) & $0.81 \pm 0.02$ & $0.72 \pm 0.02 * * *$ \\
\hline Serum cholesterol (mmol/l) & $4.7 \pm 0.1$ & $4.9 \pm 0.1 *$ \\
\hline Serum HDL cholesterol (mmol/l) & $1.4 \pm 0.04$ & $1.4 \pm 0.03$ \\
\hline Serum triglycerides $(\mathrm{mmol} / \mathrm{l})$ & - & $1.1 \pm 0.1$ \\
\hline Heart rate (beats/min) & $76 \pm 2$ & $71 \pm 1 * *$ \\
\hline ETDRS $^{f}$ score & $21 \pm 2$ & $38 \pm 2 * * *$ \\
\hline
\end{tabular}

$* p<0.05, * * p<0.01$ and $* * * p<0.001$ for changes in parameters between baseline and follow-up examination

a Reference range 4-6\%

b Glycaemic exposure (see methods)

${ }^{c}$ Reference range 50-110 for women and 55-115 $\mu \mathrm{mol} / \mathrm{l}$ for men

Table 2 Simple non-parametric (Spearman's) correlation coefficients between clinical and biochemical parameters and measures of carotid IMT d UAER, overnight urinary albumin excretion rate

e Median, interquartile range [25\%, 75\%]

${ }^{f}$ ETDRS score for grading of severity of diabetic retinopathy (score $\leq 10=$ normal [26]

\begin{tabular}{|c|c|c|c|c|c|c|}
\hline & $\begin{array}{l}\text { Mean } \\
\text { IMT } \\
(\mathrm{mm})\end{array}$ & $\begin{array}{l}\text { Maximal } \\
\text { IMT } \\
(\mathrm{mm})\end{array}$ & $\begin{array}{l}\text { Far wall } \\
\text { IMT } \\
(\mathrm{mm})\end{array}$ & $\begin{array}{l}\text { IMT of } \\
\text { CCA } \\
(\mathrm{mm})\end{array}$ & $\begin{array}{l}\text { IMT of } \\
\mathrm{CB} \\
(\mathrm{mm})\end{array}$ & $\begin{array}{l}\text { IMT of } \\
\text { ICA } \\
(\mathrm{mm})\end{array}$ \\
\hline Age of onset of diabetes (years) & $0.44^{* * *}$ & $0.46^{* * * *}$ & $0.44^{* * *}$ & $0.53^{* * *}$ & $0.23^{*}$ & $0.34^{* *}$ \\
\hline Glycaemic exposure $\left(A_{1 c} \text { months }\right)^{a}$ & 0.17 & 0.13 & 0.14 & -0.01 & $0.25^{*}$ & 0.03 \\
\hline Family history of Type II diabetes & $0.33^{* *}$ & $0.36^{* *}$ & $0.30^{* *}$ & $0.44^{* * *}$ & $0.22^{*}$ & -0.01 \\
\hline BMI $\left(\mathrm{kg} / \mathrm{m}^{2}\right)^{\mathrm{b}}$ & $0.32^{* *}$ & $0.29^{*}$ & $0.35^{\text {** }}$ & 0.21 & $0.25^{*}$ & $0.27^{*}$ \\
\hline Mean arterial blood pressure $(\mathrm{mmHg})^{\mathrm{b}}$ & 0.19 & 0.17 & $0.26^{*}$ & 0.12 & 0.12 & 0.15 \\
\hline
\end{tabular}

Only parameters which were significantly correlated with at least one of the IMT parameters are shown

${ }^{a}$ Estimate of cumulative glycaemic exposure (units above $\mathrm{HbA}_{1 \mathrm{C}} 6.0 \%$ times duration of diabetes in months)

wall carotid IMT $(r=0.23, p<0.05)$. Together these variables (Table 2 ) explained $\left(\mathrm{R}^{2}\right) 38 \%$ of mean, $39 \%$ of maximal, $37 \%$ of far wall, $38 \%$ of common carotid artery, $28 \%$ of carotid bulb, and $23 \%$ of internal carotid artery IMTs.

At the time IMT was measured (cross-sectional analysis), mean arterial blood pressure was associated with all carotid IMTs $(r \geq 30.23, p<0.05)$ except for IMT of carotid bulb and internal carotid artery. Serum LDL cholesterol was associated with the far wall IMT $\mathrm{b}$ At baseline, 10 years before measurement of IMT

$* p<0.05, * * p<0.01, * * * p<0.001$ for correlations of carotid artery in univariate analysis $(r=0.24$, $p<0.05)$. In multiple linear regression analysis including age, age of onset of diabetes, family history of Type II diabetes, family history of hypertension, and mean arterial blood pressure, serum LDL cholesterol remained the only independent predictor of carotid far wall IMT $\left(p=0.003, \mathrm{R}^{2}=39 \%\right)$.

IMT in patients divided into tertiles of glycaemic exposure. To further characterise the impact of lifetime 

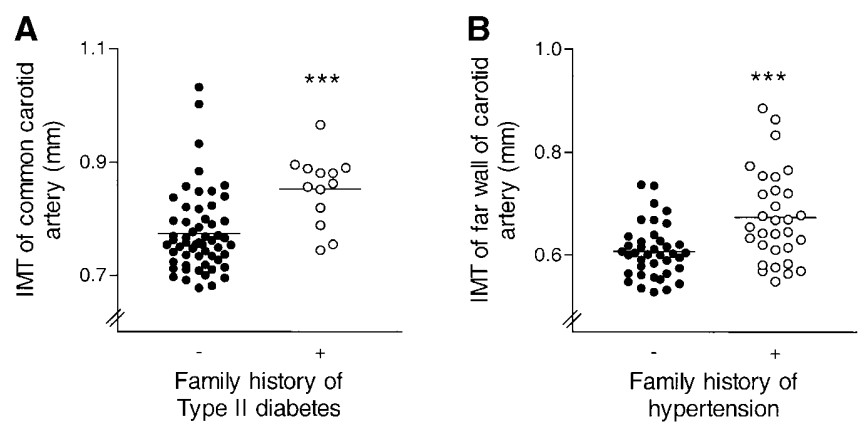

Fig. 1A, B. Common (A) and far wall (B) carotid artery IMT in patients with Type I diabetes with no family history $(-)$ or a positive family history $(+$, at least one parent affected) of Type II diabetes $(\mathbf{A})$ or hypertension $(\mathbf{B}) . * * * p<0.001$ for patients with positive (+) vs negative (-) family history of Type II diabetes or hypertension. The horizontal line denotes mean values

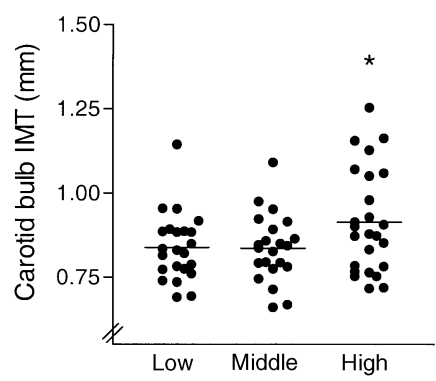

Fig. 2. Carotid bulb IMT (means \pm SEM) in patients with Type I diabetes divided into tertiles of lifetime glycaemic exposure calculated as $\mathrm{A}_{1 \mathrm{C}}$ months (see Methods). ${ }^{*} p<0.05$ for patients with highest vs middle and for highest vs lowest glycaemic exposures

glycaemic exposure on IMT, the patients were divided into tertiles based on $\mathrm{A}_{1 \mathrm{c}}$ months. Apart from complications, the tertiles were comparable. Of microvascular complications, the patients in the highest tertile of glycaemic exposure had a higher UAER - $11(8,266)$ for median and $(25 \%, 75 \%)$ interquartile range - compared with the lowest tertile $(6[6,9])$ of glycaemic exposure, and a higher ETDRS retinopathy score (52 $\pm 3, p<0.001$ for lowest tertile, $p<0.01$ for middle tertile) compared with the middle $(40 \pm 3, p<0.001$ for lowest tertile) and the lowest $(20 \pm 2)$ tertiles of glycaemic exposure. The tertiles did not differ with respect to smoking habits, alcohol consumption or present and past physical activity (data not shown).

Carotid bulb thickness was $(p<0.05)$ higher in the highest (1356 $\pm 49 \mathrm{~A}_{1 \mathrm{c}}$ months, or $\mathrm{HbA}_{1 \mathrm{c}} 5.7 \%$ above normal for 20 years) glycaemic exposure tertile than the middle (91519 $\mathrm{A}_{1 \mathrm{c}}$ months, or $\mathrm{HbA}_{1 \mathrm{c}} 3.8 \%$ above normal for 20 years) or the lowest (51531 $\mathrm{A}_{1 \mathrm{c}}$ months, or $\mathrm{HbA}_{1 \mathrm{c}} 2.1 \%$ above normal for 20 years) tertile. Individual values and means of IMT of carotid bulb in patients divided into tertiles of glycaemic exposure are shown (Fig. 2). The patients in the highest as compared to those in the middle and the lowest glycaemic tertile, also had higher mean $(0.65 \pm 0.01$ vs $0.62 \pm$ 0.01 and $0.63 \pm 0.01 \mathrm{~mm})$, maximal $(0.83 \pm 0.02 \mathrm{vs}$
$0.79 \pm 0.01$ and $0.81 \pm 0.02 \mathrm{~mm})$ and far wall $(0.66 \pm$ 0.02 vs $0.62 \pm 0.02$ and $0.62 \pm 0.01 \mathrm{~mm}$ ) IMT of carotid artery but these differences did not reach statistical significance. The IMT of internal carotid artery averaged $0.72 \pm 0.02 \mathrm{~mm}$ in the high, $0.73 \pm 0.03 \mathrm{~mm}$ in the middle, and $0.730 .03 \mathrm{~mm}$ in the low glycaemic exposure group (NS between groups).

\section{Discussion}

We determined predictors of subclinical atherosclerosis as assessed by IMT measurements of carotid arteries. The results show that in patients with Type I diabetes, a positive family history of Type II diabetes and a family history of hypertension contribute to carotid IMT at several sites independent of age, sex and duration of diabetes, whereas chronic hyperglycaemia, defined as a lifetime cumulative glycaemic exposure $\left(\mathrm{A}_{1 \mathrm{c}}\right.$ months), independently predicted only thickening of the carotid bulb.

A positive family history of Type II diabetes and hypertension in the Type I diabetic patients were both independent of all other risk factors, predictors of several measures of carotid IMT. This finding is in line with previous studies showing that a positive family history of Type II diabetes is associated with an increased risk of developing diabetic nephropathy [5] and coronary artery disease [29] in patients with Type I diabetes. First-degree relatives of patients with Type II diabetes have also been shown to have more cardiovascular risk factors, such as high BMI, higher systolic and diastolic blood pressures, higher serum insulin and triglyceride concentrations, and lower concentrations of high density lipoprotein particles, than subjects with a negative family history [30]. In multivariate analysis, thickening of carotid IMT has been positively correlated with hypertension [31, 32], microalbuminuria [33], serum total and LDL cholesterol [9], low HDL cholesterol [9, 31], serum triglycerides [9, 34], and a high BMI [35] in patients with Type II diabetes. In hypertension, thickening of carotid IMT has also been a frequent finding $[36,37]$. In our study, triglycerides were only measured at the follow-up examination and did not correlate with measures of IMT.

A difference in this study compared with previous studies in patients with Type I diabetes is that we included measurement of the IMT of the carotid bulb. It is fairly well established that patients with Type I diabetes have a more diffuse and distal disease in carotid $[38,39]$ and coronary arteries [40] than non-diabetic subjects. This is in contrast to Type II diabetes, where atherosclerosis, according to more recent studies using quantitative angiography and carefully matched control subjects, seems to be similar to that in non-diabetic subjects [41]. We found, as in previous studies in Type I diabetes where usually common $[13,14,15,16,17$, $18,19,20]$ and internal [16] carotid IMT were mea- 
sured, classic cardiovascular risk factors including age, blood pressure and LDL cholesterol to correlate with these measures of IMT, while glycaemic exposure was only correlated with bulb IMT. Thus, hyperglycaemia possibly damages the arterial tree at sites different from those affected by classic risk factors. Moreover, glycaemic control does not predict coronary heart disease overall but does predict peripheral vascular disease, whereas classic risk factors such as hypertension are more closely related to coronary heart disease than to peripheral vascular disease in patients with Type I diabetes [42, 43, 44]. Many biochemical mechanisms could explain why hyperglycaemia independent of other cardiovascular risk factors can increase IMT. In vitro glucose potentiates vascular smooth muscle cell growth and accumulation of irreversible glycated proteins in the arterial wall [45], it also increases extracellular collagen content [46], and can accelerate oxidation and trapping of lipoprotein particles [47] into vascular wall thus increasing arterial IMT.

Mild hyperglycaemia [8, 11, 48], increased postprandial plasma glucose concentrations [12] and slight increases in $\mathrm{HbA}_{1 \mathrm{c}}$ [49] have been associated with increased carotid IMT in non-diabetic subjects. In crosssectional studies in patients with Type I diabetes, associations between $\mathrm{HbA}_{1 \mathrm{c}}$ and mean carotid IMTs have been found $[14,17]$. In other studies, however, single measures of glycaemia such as the fasting blood glucose or the $\mathrm{HbA}_{1 \mathrm{c}}$ concentration have not correlated with carotid IMT in patients with Type I diabetes $[13,15,16,18,19,20]$. This was also true in our study whereby the $\mathrm{HbA}_{1 \mathrm{c}}$ measurements carried out 10 years before and at the time of IMT measurements were not correlated with carotid IMT. This could be either because glycaemic control is a relatively weak predictor of macrovascular complications compared with other risk factors of cardiovascular disease, or because a simple measurement poorly reflects the impact of overall glycaemia on IMT. These data support the proposal [27] that cumulative glycaemic exposure $\left(\mathrm{A}_{1}\right.$ months), a measure of lifetime glycaemia, provides a valuable tool to assess lifetime chronic hyperglycaemia and is therefore superior to single cross-sectional measures of glycaemia. We assessed life-time glycaemia and found that only when lifetime glycaemic exposure averaged $5.7 \%$ above normal for 20 years (or $11.4 \%$ above normal for 10 years) it was associated with an increase in IMT of the carotid bulb. However, unlike data on glycaemic control, in our study only two standardised measurements (at baseline and at the follow-up visit) of blood pressure and lipid parameters were available. This, and the relatively small size of the study population, might have underestimated the ability of these risk factors to predict IMT in the Type I diabetic patients.

The influence of improved glycaemic control on IMT has been examined in two studies. In the first study [20], $\mathrm{HbA}_{1 \mathrm{c}}$ was maintained at 7.1 or $8.2 \%$ for
10 years using intensified or standard insulin treatment. The patients in the standard group had stiffer arteries, endothelial dysfunction and thicker intima-media in the left common carotid artery than the group receiving standard therapy. Nevertheless, $\mathrm{HbA}_{1 \mathrm{c}}$ measured 29 times per patient over a 10-year period did not correlate with IMT. In the DCCT or EDIC study [16], IMT of the common and internal carotid arteries were measured after maintaining $\mathrm{HbA}_{1 \mathrm{c}}$ at $7.3 \%$ or $9.0 \%$ for a 10 -year period. In this study neither $\mathrm{HbA}_{1 \mathrm{c}}$ at baseline nor treatment group explained variation in measures of IMT. In the DCCT or EDIC study [16], patients with hypertension, hyperlipidaemia and known coronary artery disease at baseline were excluded, which could, in addition to the limited data on glycaemic exposure have contributed to small (thicker internal carotid artery IMT in diabetic men but not women) or non-significant (common carotid artery IMT in both men and women) differences in IMT between diabetic patients and non-diabetic subjects.

Our study encourage the use of tools such as IMT measurements for early detection of macrovascular disease in patients with Type I diabetes. It also supports epidemiological data, which have shown glycaemic control to be an independent predictor of cardiovascular events in Type I diabetes, though there are no studies documenting that an increase in IMT can be prevented by intensive blood glucose control. Our data also suggest that a positive family history of Type II diabetes or hypertension increases IMT independent of glycaemic control in patients with Type I diabetes. Therefore, early preventive care should be taken of all known cardiovascular risk factors especially in those patients with Type I diabetes who have a positive family history of Type II diabetes or hypertension.

Acknowledgements. Supported by grants from the Academy of Finland, the Finnish Foundation for Diabetes Research, the Novo-Nordisk Foundation, the Sigrid Juselius Foundation $(\mathrm{H}$. Yki-Järvinen), the Finnish Cultural Foundation (A. Schlenzka), and the Finnish Medical Association Duodecim (S. Mäkimattila). We thank J. Mäenpää, MD, N-P Huttunen, MD, H. Erkkilä, MD, L. Mykkänen, MD, and the volunteers for their help. M. Haikola and K. Tuomola are acknowledged for their excellent technical assistance.

\section{References}

1. Krolewski AS, Kosinski AS, Warram JH et al. (1987) Magnitude and determinants of coronary artery disease in juvenile-onset, insulin-dependent diabetes mellitus. Am J Cardiol 59: 750-755

2. Christlieb AR, Warram JH, Krolewski AS et al. (1981) Hypertension: the major risk factor in juvenile-onset insulindependent diabetics. Diabetes 30: 90-96

3. Jensen T, Borch-Johnsen K, Kofoed-Enevoldsen A, Deckert T (1987) Coronary heart disease in young Type I (insulin-dependent) diabetic patients with and without diabetic nephropathy: incidence and risk factors. Diabetologia 30: $144-148$ 
4. Lehto S, Rönnemaa T, Pyörälä K, Laakso M (1999) Poor glycemic control predicts coronary heart disease events in patients with type 1 diabetes without nephropathy. Arterioscler Thromb Vasc Biol 19: 1014-1019

5. Fagerudd JA, Petterson-Fernholm KJ, Grönhagen-Riska C, Groop P-H (1999) The impact of a family history of Type II (non-insulin-dependent) diabetes mellitus on the risk of diabetic nephropathy in patients with Type I (insulindependent) diabetes mellitus. Diabetologia 42: 519-526

6. Pingoli P, Tremoli E, Poli A, Oreste P, Paoletti R (1986) Intimal plus medial thickness of the arterial wall: a direct measurement with ultrasound imaging. Circulation 74: 1399-1406

7. Salonen R, Salonen JT (1990) Progression of carotid atherosclerosis and its determinants: a population-based ultrasonography study. Atherosclerosis 81: 33-40

8. Yamasaki Y, Kawamori R, Matsushima H et al. (1995) Asymptomatic hyperglycaemia is associated with increased intimal plus medial thickness of the carotid artery. Diabetologia 38: 585-591

9. el-Barghouti N, Elkeles R, Nicolaides A, Geroulakos G, Dhanjil S, Diamond J (1997) The ultrasonic evaluation of the carotid intima-media thickness and its relation to risk factors of atherosclerosis in normal and diabetic population. Int Angiol 16: 50-54

10. Pan WH, Bai CH, Chen JR, Chiu HC (1997) Association between carotid atherosclerosis and high factor VIII activity, dyslipidemia, and hypertension. Stroke 28: 88-94

11. Temelkova-Kurktschiev T, Koehler C, Schaper F et al. (1998) Relationship between fasting plasma glucose, atherosclerosis risk factors and carotid intima media thickness in non-diabetic individuals. Diabetologia 41: 706712

12. Hanefeld M, Koehler C, Schaper F, Fuecker K, Henkel E, Temelkova-Kurktschiev T (1999) Postprandial plasma glucose is an independent risk factor for increased carotid intima-media thickness in non-diabetic individuals. Atherosclerosis 144: 229-235

13. Frost D, Beisiegel U (1998) Determinants of carotid artery wall thickening in young patients with type 1 diabetes mellitus. Diabet Med 15: 851-857

14. Yamasaki Y, Kawamori R, Matsushima H et al. (1994) Atherosclerosis in carotid artery of young IDDM patients monitored by ultrasound high-resolution B-mode imaging. Diabetes 43: 634-639

15. Giannattasio C, Failla M, Grappiolo A, Gamba PL, Paleari F, Mancia G (2001) Progression of large artery structural and functional alterations in Type 1 diabetes. Diabetologia 44: 203-208

16. Epidemiology of Diabetes Interventions and Complications (EDIC) Research Group (1999) Effect of intensive diabetes treatment on carotid artery wall thickness in the epidemiology of diabetes interventions and complications. Diabetes 48: $383-390$

17. Kanters SDJM, Algra A, Banga J-D (1997) Carotid intima-media thickness in hyperlipidemic type I and type II diabetic patients. Diabetes Care 20: 276-280

18. Merrin PK, Renton S, Fisher C, et al. (1994) Serum lipids and apolipoproteins and their relationship with macrovascular disease in type 1 diabetes. Diabet Med 11: 402-406

19. Frost D, Pfohl M, Clemens P, Häring H-U, Beischer W (1998) Evaluation of the insertion/deletion ACE gene polymorphism as a risk factor for carotid artery intima-media thickening and hypertension in young type 1 diabetic patients. Diabetes Care 21: 836-840

20. Jensen-Urstad KJ, Reichard PG, Rosfors JS, Lindblad LEL, Jensen-Urstad MT (1996) Early atherosclerosis is re- tarded by improved long-term blood glucose control in patients with IDDM. Diabetes 45: 1253-1258

21. Stratton IM, Adler AI, Neil HAW et al. (2000) Association of glycemia with macrovascular and microvascular complications of type 2 diabetes (UKPDS 35): prospective observational study. BMJ 321: 405-412

22. Kriska AM, Knowler WC, La Porte RE et al. (1990) Development of questionnaire to examine relationship of physical activity and diabetes in Pima Indians. Diabetes Care 13: 401-411

23. Rose GA, Blackburn H (1968) Cardiovascular survey methods. WHO Monograph Series No 56, World Health Organization, Geneva

24. Selzer RH, Hodis HN, Kwong-Fu H et al. (1994) Evaluation of computerized edge tracking for quantifying intima-media thickness of the common carotid artery from B-mode ultrasound images. Atherosclerosis 111: 1-11

25. American Diabetes Association and the National Kidney Foundation (1994) Consensus development conference on the diagnosis and management of nephropathy in patients with diabetes mellitus. Diabetes Care 17: 1357-1361

26. Davis MD, Fisher MR, Gangnon E et al. for the Early Treatment Diabetic Study Research Group (1998) Risk factors for high-risk proliferative diabetic retinopathy and severe visual loss: Early Treatment Diabetes Retinopathy Study Report \#18. Invest Ophthalmol Vis Sci 39: 233-252

27. Orchard TJ, Forrest KYZ, Ellis D, Becker DJ (1997) Cumulative glycemic exposure and microvascular complications in insulin-dependent diabetes mellitus: the glycemic threshold revisited. Arch Intern Med 157: 1851-1856

28. Friedewald WT, Levy R, Fredrickson DS (1972) Estimation of the concentration of low-density lipoprotein cholesterol in plasma without use of the preparative ultracentrifuge. Clin Chem 18: 499-502

29. Erbey JR, Kuller LH, Becker DJ, Orchard TJ (1998) The association between family history of type 2 diabetes and coronary artery disease in type 1 diabetes population. Diabetes Care 21: 610-611

30. Haffner SM, Stern MP, Hazuda HP, Mitchell BD, Patterson JK, Ferrannini E (1989) Parental history of diabetes is associated with increased cardiovascular risk factors. Arteriosclerosis 9: 928-933

31. Pujia A, Gnasso A, Irace C, Colonna A, Mattioli PL (1994) Common carotid arterial wall thickness in NIDDM subjects. Diabetes Care 17: 1330-1336

32. Bonora E, Tessari R, Micciolo R et al. (1997) Intimalmedial thickness of the carotid artery in nondiabetic and NIDDM patients. Relationship with insulin resistance. Diabetes Care 20: 627-631

33. Mykkänen L, Zaccaro DJ, O'Leary DH, Howard G, Robbins DC, Haffner SM (1997) Microalbuminuria and carotid artery intima-media thickness in nondiabetic and NIDDM subjects. The Insulin Resistance Atherosclerosis Study (IRAS). Stroke 28: 1710-1716

34. Kong C, Elatrozy T, Anyalku V, Robinson S, Richmond W, Elkeles RS (2000) Insulin resistance, cardiovascular risk factors and ultrasonically measured early arterial disease in normotensive Type 2 diabetic subjects. Diabetes Metab Res Rev 16: 448-453

35. Guvener N, Tutuncu NB, Oto A, Erbas T (2000) Major determinants of the carotid intima-media thickness in type 2 diabetic patients: age and body mass index. Endocr J 47: 523-533

36. Hughes AD, Sinclair AM, Geroulakos G et al. (1993) Structural changes in the heart and carotid arteries associated with hypertension in humans. J Hum Hypertens 7: 395-397 
37. Armentano RL, Graf S, Barra JG et al. (1998) Carotid wall viscosity increase is related to intima-media thickening in hypertensive patients. Hypertension 31: 534-539

38. Crall FV Jr, Roberts WC (1978) The extramural and intramural coronary arteries in juvenile diabetes mellitus. Analysis of nine necropsy patients aged 19 to 38 years with onset of diabetes before age 15 years. Am J Med 64: 221230

39. Valsania P, Zarich SW, Kowalchuk GJ, Kosinski AS, Warram JH, Krolewski AS (1991) Severity of coronary artery disease in young patients with insulin-dependent diabetes mellitus. Am Heart J 122: 695-700

40. Pajunen P, Taskinen M-R, Nieminen MS, Syvänne M (2000) Angiographic severity and extent of coronary artery disease in patients with type 1 diabetes mellitus. Am J Cardiol 86: 1080-1085

41. Pajunen P, Nieminen MS, Taskinen M-R, Syvänne M (1997) Quantitative comparison of angiographic characteristics of coronary artery disease in patients with non-insulin-dependent diabetes mellitus compared with matched non-diabetic control subjects. Am J Cardiol 80: 550-556

42. Klein R (1995) Hyperglycemia aned microvascular and macrovascular disease in diabetes. Diabetes Care 18: 258 268
43. Koivisto VA, Stevens LK, Mattock M et al. (1996) Cardiovascular disease and its risk factors in IDDM in Europe. Diabetes Care 19: 689-697

44. Forrest KY-Z, Becker DJ, Kuller LH, Wolfson SK, Orchard TJ (2000) Are predictors of coronary heart disease and low-extremity arterial disease in type 1 diabetes the same? A prospective study. Atherosclerosis 148: 159-169

45. Rumble JR, Cooper ME, Soulis T et al. (1997) Vascular hypertrophy in experimental diabetes. Role of advanced glycation end products. J Clin Invest 99: 1016-1027

46. Turk Z, Misur I, Turk N, Benko B (1999) Rat tissue collagen modified by advanced glycation: correlation with duration of diabetes and glycemic control. Clin Chem Lab Med 37: $813-820$

47. Lyons TJ (1993) Glycation and oxidation: a role in the pathogenesis of atherosclerosis. Am J Cardiol 71: 26B-31B

48. Temelkova-Kurktschiev T, Henkel E, Schaper F, Koehler C, Siegert G, Hanefeld M (2000) Prevalence and atherosclerosis risk in different types of non-diabetic hyperglycemia. Is mild hyperglycemia an underestimated evil? Exp Clin Endocrinol Diabetes 108: 93-99

49. Vitelli LL, Shahar E, Heiss G et al. (1997) Glycosylated hemoglobin level and carotid intima-media thickening in nondiabetic individuals. Diabetes Care 20: 1454-1458 